\title{
Preparing the Startup Ecosystem for Building a New Startup Business During Pandemic: A Systematic Literature Review
}

\author{
Ariani Dwi Wulandari \\ Department of Information Systems, Institut Teknologi Sepuluh Nopember \\ arianidwiw@gmail.com \\ Apol Pribadi Subriadi \\ Department of Information Systems, Institut Teknologi Sepuluh Nopember \\ apol@is.its.ac.id
}

\begin{abstract}
The success of the startup planning in the early stages of business development would make it easier to achieve the business target and proceed to the next phase. This study aims to obtain information on each ecosystem element's role in the early stages of startup development. The literature review method was adopted by collecting the last ten years of journals. Forty-six primary journals were generated from filtering the journals with relevant topic issues. Then $17 \%$ of the evaluation type journals, $24 \%$ of validation journals and solutions, and 35\% of experience journals. The Results are the ecosystem element's position at the startup growth stage in general. This knowledge could assist the founders' research plan for startup market creation to mitigate startup failure rates in the first few years. Guidance on several topics that apply to further study also provides in this journal.
\end{abstract}

Keywords: Startup, Ecosystem Element Contribution, Early Stages Development, Literature Review

\section{INTRODUCTION}

The startup ecosystem needs to be managed to sustain market continuity and growth. The eight ecosystem elements were translated by [1]: entrepreneur, support factors, finance, demography, market, education, human capital, and technology. Each element could consist of several sub-elements having different contributions to the business. [26 ] reported that one of the main elements supporting the growth in innovation and value of startup products had become a focus in creating a business ecosystem. The description of each ecosystem element and its relevance to the startup business is addressed separately. Subsequently, the study results' variation is induced by the 
different types of startups in the research object (such as finance, education, and technology).

The study of the prioritization of the main ecosystem elements development previously carried out on a software startup. The technology was identified as the key element with the highest effect on business, followed by the other five elements [1]. Other studies analyze the management of financial aspects in the initial startup development process [7], and the number of research results described in section 2. Then, whether the effect of the startup ecosystem elements on business sustainability is the same as that of the ecosystem elements at the outset of business growth, that is why this study issue was generated.

RQ: How does the new startup in the pandemic era prepare their ecosystem elements to optimize their goals?

This journal presented the research background in section 1. The appropriate theoretical basis to discuss this problem (section 2). Explanation of the flow and research method (section 3). This study will enrich the research literature on the ecosystems' contribution to the early-stage development process (section 4), expand the study of ecosystems' contribution to developing startups from an early age, and direct relevant future research topics (section 5). Then conclusion from this study in (section 6).

\section{LITERATURE REVIEW}

\subsection{Startup Development}

A startup is defined as a venture company or an entrepreneur in conditions of extreme uncertainty [1], has a high decision-making pace, and a strong potential to take advantage of business opportunities [8, 9]. However, startups have less experience [10], such as in operations and production profiles [7]. It is also fragile when it comes to starting a collaboration with companies [11]. Risk opportunities have to be mitigated and managed as best as possible. Entrepreneurial coaching is one of the parties that will help startups solve market challenges [4]. Entrepreneurs and analysts pay greater attention to startups because of their willingness to adapt technologies, business models, services, and products [9].

Building a successful corporate strategy must consider several factors, the right price, the speed of integration, and different organizational cultures [9]. Each of these factors is built through various stages [12]. Recently there is a method often used and discussed by researchers called lean startup methodology. The results of these studies explain that the lean startup method has a cycle, first dissecting a business idea in the form of a business model canvas. Second, make a test to test the quality of the product they have. Third, make decisions about the appropriate product market where customers are willing to pay the value of the product offered [4]. In some conditions, startup development requires better preparation and adaptation maturity [13]. 


\subsection{Startup Ecosystem}

In this context, ecosystems are being interpreted as an operational environment and composed of interactive elements [10], serving as a learning medium in the startup development process to improve retail revenue on a larger scale [14]. Ecosystem growth impacts creating a new startup [3,15], as the learning process continues to this day. Startup failure in the first few years (development period) is still attributed to a lack of minimum product value (MPV) [10]. Therefore, the literature on the role of environmental awareness in early startup growth could be required to achieve an appropriate business objective. Then it can be introduced as an environment that exists in particular regions [1]. There are four phases in developing the startup ecosystem: formation, development, leadership, and self-renewal, all of which have distinct challenges [8]. A company must continually respond to a dynamic business environment $[2,14,16]$, including changes in technologies, legislation, and consumer demands related to environmental factors (especially during a pandemic).

Ecosystems are also related to business and entrepreneurship. The business ecosystem is defined as the environment that describes the company's network, resulting in a holistic, integrated technology system that generates customer value. Its survival is influenced by ecosystem members, endogenous and exogenous factors of ecosystem evolution, ecosystem change dynamics, and company strategic considerations [17]. An entrepreneurial ecosystem is a group of interdependent actors in a geographic area that influence the formation and final trajectory of all groups of actors and the economy's potential as a whole. The entrepreneurial ecosystem evolves through a set of interdependent components that interact to produce the creation of new ventures [10].

\subsection{Smart Product and Innovation of Startup Business}

Developing a new business means offering a product or service under high competitive pressure. Technology-based startups will have innovation and a passion for creating innovations in the market for achieving competitive advantages and improve survival likelihood [5]. An idea is the primary determinant of new business development [15]. Innovation is related to creativity, how to generate the previously unknown, or make a difference in simple ideas and transform the ideas into a product [18]. Startup products are usually built with high-quality potential target markets [12], can be classified into hardware and software startups [10]. Creating an innovation can be accomplished by open innovation, where the person asks each other questions about the choice of technologies, consumer needs, and disruptions. [16]. One factor for building product innovation is finding the right partner with built-in business goals [11]. Mergers and acquisitions (M\&A) can also contribute to transformative disruption [9] points out.

\section{LENGTH REQUIREMENTS}

Based on the methodology developed by [11], the literature review model research begins with defining objectives, gathering related literature, filtering the literature, and 
extracting the appropriate data. This method is commonly used when many academics have presented the research subject used [10], illustrated in Figure 1.

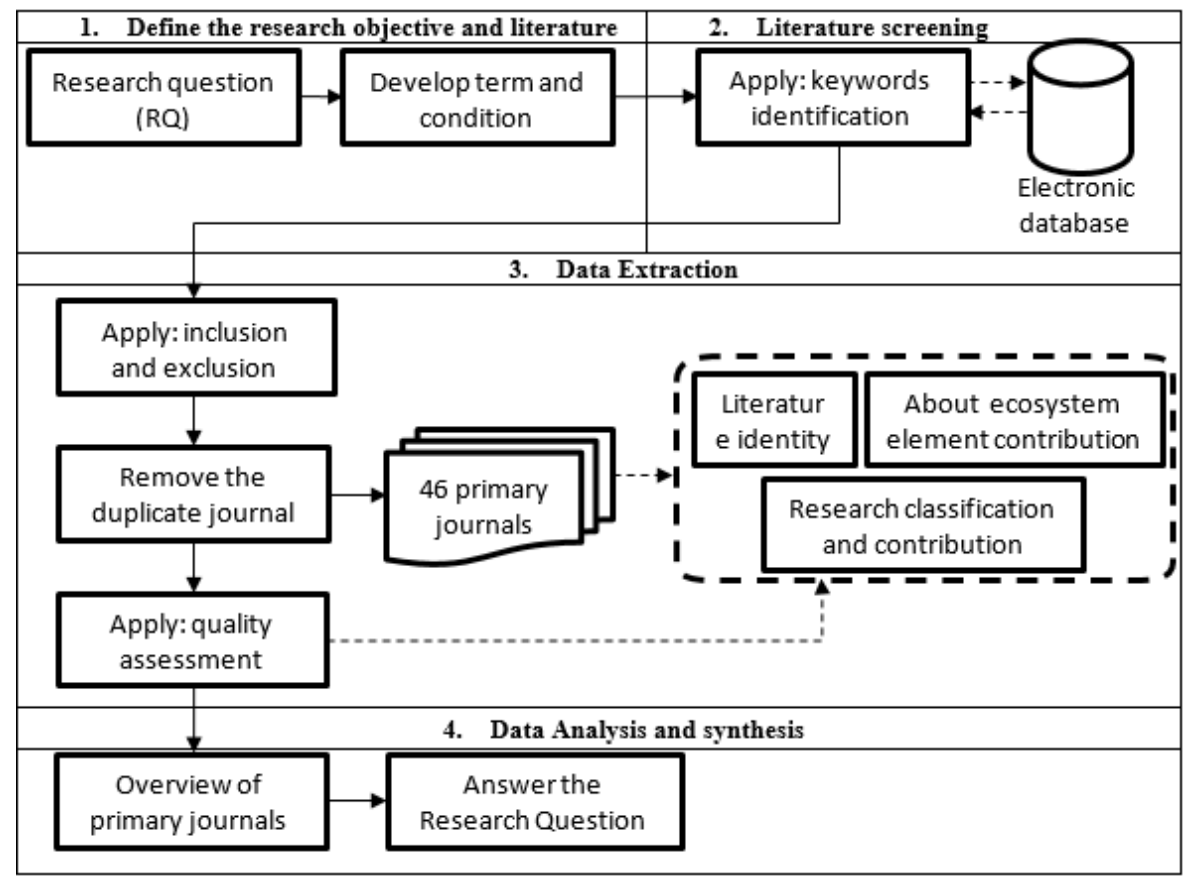

Figure 1. Research methodology

Journals relevant to research topics are searched in Direct and Emerald electronic science databases using startup keywords and ecosystem elements. The journal analysis was then performed using inclusion and exclusion criteria. Focus on the titles, abstracts, and keywords that match the following terms (I) in the first stage of the search: (E): Exclusion and (I): Inclusion:

- (I): Contains the keywords "Startup" and each element of the startup ecosystem, namely demography, education, entrepreneurship, finance, human capital, market, support factors, technology, and startup business development.

- (E): Journal is not in English because it will complicate the analysis process.

- (E): Journal is not available or must first request access to get the full version.

- (E): Does not focus on startup elements that influence business activities (such as algorithms and networks).

After collecting 46 related journals, consider each journal in more detail to summarize the problems, theories, methods, findings, and then look for a research gap. Finally, assess its quality using some established conditions.

\subsection{Data Extraction}

\section{Quality assessment}

The selected journal must fulfill one of the research classifications used by [10]: 
- Evaluation - gives an option which is the better one for some cases.

- Solution - provide solutions to issues and problems in the research topic.

- Experience - reflects the expertise of the writer or organization on the subject of research.

- Validation - confirm and analyze the truth of a solution offered by research.

Besides the parameters set out above, the journal must also refer to one or more of the following points:

- Technique or procedure - new methods as a helpful way to finish work.

- Model or framework - model construction of interesting phenomena or data set analysis.

- Specific solution - solutions intended for the resolution of certain problems.

- Report-observation result of the phenomena.

The following criteria below are used to get the answers from RQ.

- The journal provides information on how to build a new startup or entrepreneur.

- The journal provides assessments and knowledge about the contribution of each ecosystem element to business development.

Journal's findings with these requirements would be labeled and then reviewed to ensure that the data obtained from any of the chosen journal articles meet all the standards compared to hundreds of other publications. This process was repeated twice to overcome bias in the election results.

\subsection{Data Analysis}

A summative content analysis approach was used to analyze data from each journal [19]. The first step in data analysis is to pay attention to keywords from each reference journal. The keywords are taken from each section of the journal and refer to elements of the startup ecosystem. Each keyword used in the journal must also be relevant to the context of this research topic. Details on each of the 46 journals as seen in Figure 2 and Figure 3. Several journals are further discussed in section 4. A journal may contribute to a variety of elements of the environment. For example, P37 explores how internet technology has changed people's perception of goods. This trend can also connect to a promotional strategy in the consumer element.

\section{RESULT AND DISCUSSION}

\subsection{Overview}

All the literature used was written in the timeframe 2015-2020. This identification aims to assess the importance of each aspect of the environment's circumstances in dealing with current market issues. Two journals of 2015 were reviewed, three journals in 2016, 1 journal in 2017, increased to 5 journals in 2018, 16 journals in 2019, and 17 journals in 2020 (Figure 3). This large increase indicates that the startup problem has become an exciting subject in the research field, particularly in the last two years. Digital company has succeeded in becoming anchored in people lives, distorting local 
economies [20] and being one of the companies that have impacted rising government revenues [21].

Journal topics on each ecosystem element in 46 selected journals also have different distribution (Figure 2), ten journals on entrepreneurial issues, 23 journals on technology, 17 journals on finance, 11 journals on education, 12 journals on demography, 12 journals about markets, 17 journals about human capital, and 16 journals about support factors. The topic of technology to do with current business research is that technological development can affect various innovations in the business world [14], both to present new products, estimate business processes, and as a marketing strategy. List of journals related to each element in Table 1. Then See Table 3 for reference journals.

After obtaining primary journal identity data, each journal's classification and contribution were examined to determine the research result. Table 2 shows $17 \%$ of the evaluation type journals, $24 \%$ of the validation and solution journals, then $35 \%$ of the experience journals. Three Technique or protocol journals, eight Framework or model journals, nine Specific solution journals, and report journal totaled 26. To summarize, the classification and contribution of research journals, as seen in Figure 4. Most journals are categorized as experience journals, demonstrating much study that has been conducted practically to know firsthand how each element influences market continuity. In this analysis, combining these four categorized journals could be an adequate guide for the RQ response. Each will be discussed separately in the next section.

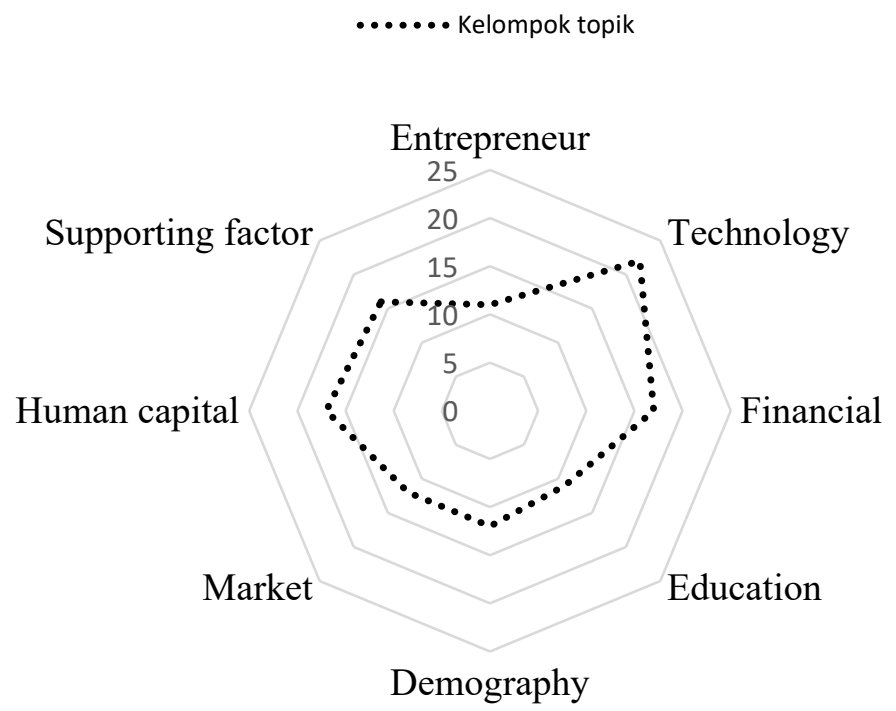

Figure 2. Distribution of journals topics 


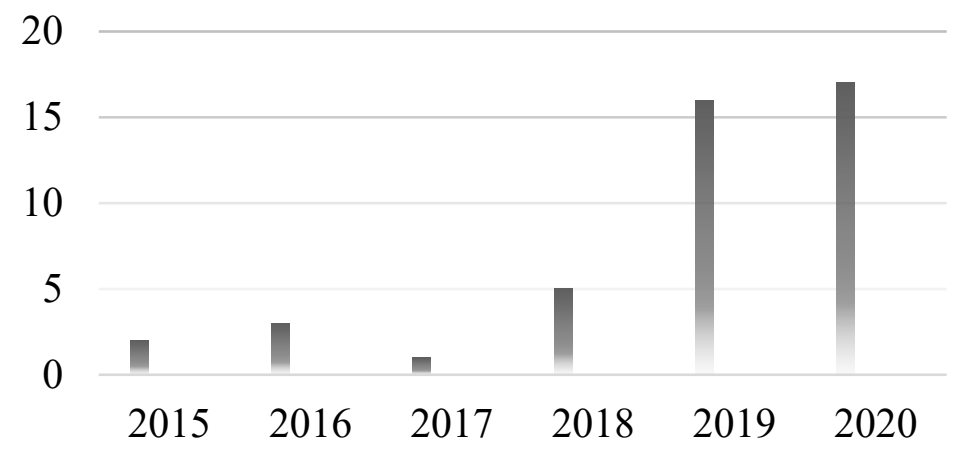

Figure 3. Distribution of research

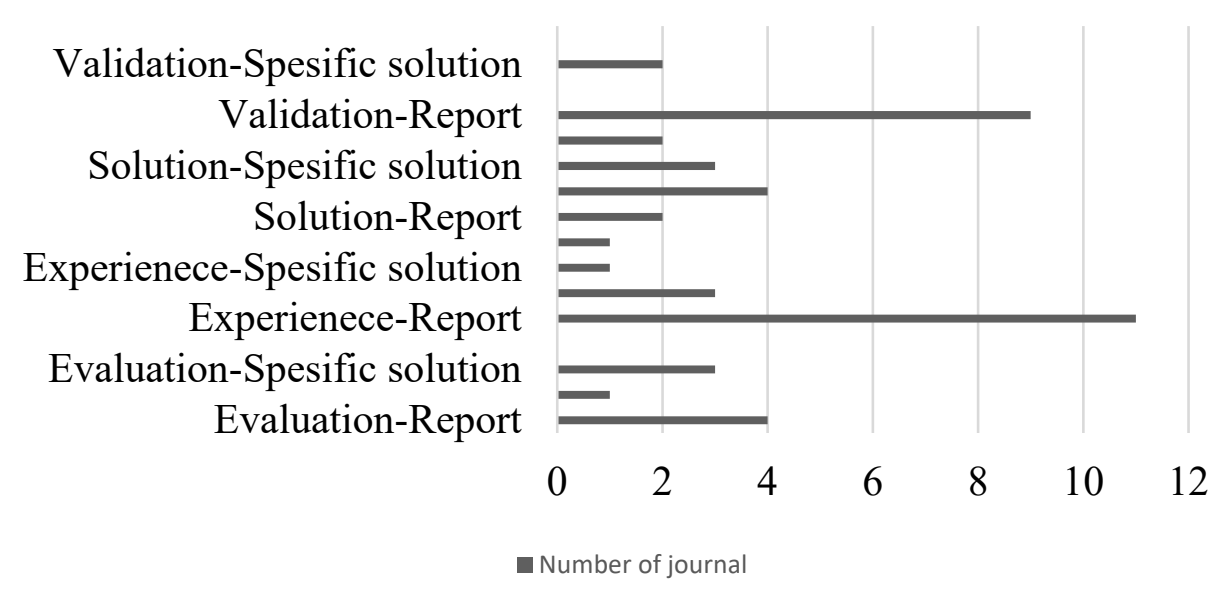

Figure 4. Journal classification and contribution overview

Table 1. Journal of element ecosystem

\begin{tabular}{ll}
\hline Element & Journals \\
\hline Demography & {$[\mathrm{P} 2, \mathrm{P} 3, \mathrm{P} 9, \mathrm{P} 15, \mathrm{P} 20, \mathrm{P} 21, \mathrm{P} 23 \mathrm{P} 25, \mathrm{P} 26, \mathrm{P} 31, \mathrm{P} 32, \mathrm{P} 33]$} \\
\hline Education & {$[\mathrm{P} 2, \mathrm{P} 4, \mathrm{P} 5, \mathrm{P} 6, \mathrm{P} 11, \mathrm{P} 20, \mathrm{P} 24, \mathrm{P} 25, \mathrm{P} 26, \mathrm{P} 27, \mathrm{P} 46]$} \\
\hline Entrepreneur & {$[\mathrm{P} 1, \mathrm{P} 2, \mathrm{P} 11, \mathrm{P} 12, \mathrm{P} 20, \mathrm{P} 24, \mathrm{P} 25, \mathrm{P} 36, \mathrm{P} 38, \mathrm{P} 45]$} \\
\hline Financial & {$[\mathrm{P} 1 \mathrm{P} 2, \mathrm{P} 8, \mathrm{P} 17, \mathrm{P} 19, \mathrm{P} 20, \mathrm{P} 22, \mathrm{P} 23, \mathrm{P} 27, \mathrm{P} 32, \mathrm{P} 33, \mathrm{P} 34, \mathrm{P} 35$,} \\
& $\mathrm{P} 36, \mathrm{P} 39, \mathrm{P} 40, \mathrm{P} 45]$ \\
\hline Human capital & {$[\mathrm{P} 1, \mathrm{P} 2, \mathrm{P} 8, \mathrm{P} 9 \mathrm{P} 11, \mathrm{P} 12, \mathrm{P} 15, \mathrm{P} 20, \mathrm{P} 21, \mathrm{P} 25, \mathrm{P} 26, \mathrm{P} 27, \mathrm{P} 28$,} \\
& $\mathrm{P} 29, \mathrm{P} 30, \mathrm{P} 44, \mathrm{P} 45]$ \\
\hline Market & {$[\mathrm{P} 1, \mathrm{P} 2, \mathrm{P} 10, \mathrm{P} 12, \mathrm{P} 14, \mathrm{P} 16, \mathrm{P} 17, \mathrm{P} 21, \mathrm{P} 31, \mathrm{P} 37, \mathrm{P} 41, \mathrm{P} 45, \mathrm{P} 46]$} \\
\hline Support factors & {$[\mathrm{P} 1, \mathrm{P} 2, \mathrm{P} 3, \mathrm{P} 4, \mathrm{P} 6, \mathrm{P} 7, \mathrm{P} 8, \mathrm{P} 14, \mathrm{P} 20, \mathrm{P} 21, \mathrm{P} 24, \mathrm{P} 32, \mathrm{P} 35, \mathrm{P} 39$,} \\
& $\mathrm{P} 40, \mathrm{P} 45, \mathrm{P} 46]$ \\
\hline Technology & {$[\mathrm{P} 1, \mathrm{P} 2, \mathrm{P} 3, \mathrm{P} 10, \mathrm{P} 13, \mathrm{P} 14, \mathrm{P} 15, \mathrm{P} 16, \mathrm{P} 17, \mathrm{P} 18 \mathrm{P} 19, \mathrm{P} 21, \mathrm{P} 25$,} \\
& $\mathrm{P} 30, \mathrm{P} 31, \mathrm{P} 32, \mathrm{P} 33, \mathrm{P} 35, \mathrm{P} 37, \mathrm{P} 42, \mathrm{P} 43, \mathrm{P} 44]$ \\
\hline
\end{tabular}


Table 2. Journal classification and contribution

\begin{tabular}{|c|c|c|c|c|c|}
\hline ID & Classification & Contribution & ID & Classification & Contribution \\
\hline $\mathrm{P} 1$ & Evaluation & Repot & $\mathrm{P} 2$ & Experience & Report \\
\hline P3 & Validation & Report & P4 & Validation & Report \\
\hline P5 & Solution & Framework & P6 & Validation & Report \\
\hline P7 & Experience & Report & P8 & Experience & $\begin{array}{l}\text { Specific } \\
\text { solution }\end{array}$ \\
\hline P9 & Validation & Report & P10 & Validation & Report \\
\hline P11 & Validation & Report & P12 & Experience & Model \\
\hline P13 & Solution & Report & P14 & Experience & Report \\
\hline P15 & Solution & Framework & P16 & Experience & Report \\
\hline P17 & Solution & Framework & P18 & Evaluation & $\begin{array}{l}\text { Specific } \\
\text { solution }\end{array}$ \\
\hline P19 & Solution & $\begin{array}{l}\text { Specific } \\
\text { solution }\end{array}$ & P20 & Evaluation & Report \\
\hline P21 & Experience & Report & P22 & Evaluation & Report \\
\hline P23 & Solution & Report & P24 & Experience & Report \\
\hline P25 & Evaluation & Report & P26 & Experience & Report \\
\hline P27 & Validation & $\begin{array}{l}\text { Specific } \\
\text { solution }\end{array}$ & P28 & Experience & Report \\
\hline P29 & Validation & $\begin{array}{l}\text { Specific } \\
\text { solution }\end{array}$ & $\mathrm{P} 30$ & Experience & Report \\
\hline P31 & Solution & Framework & P32 & Experience & Report \\
\hline P33 & Experience & Report & P34 & Validation & Report \\
\hline P35 & Solution & Procedure & P36 & Validation & Report \\
\hline P37 & Solution & $\begin{array}{l}\text { Specific } \\
\text { solution }\end{array}$ & P38 & Evaluation & $\begin{array}{l}\text { Specific } \\
\text { solution }\end{array}$ \\
\hline P39 & Solution & $\begin{array}{l}\text { Specific } \\
\text { solution }\end{array}$ & P40 & Experience & Framework \\
\hline P41 & Validation & Report & P42 & Solution & Technique \\
\hline P43 & Evaluation & Framework & P44 & Experience & Model \\
\hline P45 & Evaluation & $\begin{array}{l}\text { Specific } \\
\text { solution }\end{array}$ & P46 & Experience & Technique \\
\hline
\end{tabular}


Table 3. Journal identity

\begin{tabular}{lccccc}
\hline ID & Article & ID & Article & ID & Article \\
\hline P1 & {$[1]$} & P16 & {$[22]$} & P31 & {$[14]$} \\
\hline P2 & {$[10]$} & P17 & {$[23]$} & P32 & {$[24]$} \\
\hline P3 & {$[25]$} & P18 & {$[12]$} & P33 & {$[22]$} \\
\hline P4 & {$[4]$} & P19 & {$[26]$} & P34 & {$[21]$} \\
\hline P5 & {$[3]$} & P20 & {$[22]$} & P35 & {$[20]$} \\
\hline P6 & {$[5]$} & P21 & {$[8]$} & P36 & {$[23]$} \\
\hline P7 & {$[2]$} & P22 & {$[6]$} & P37 & {$[29]$} \\
\hline P8 & {$[16]$} & P23 & {$[24]$} & P38 & {$[25]$} \\
\hline P9 & {$[18]$} & P24 & {$[32]$} & P39 & {$[33]$} \\
\hline P10 & {$[32]$} & P25 & {$[34]$} & P40 & {$[36]$} \\
\hline P11 & {$[15]$} & P26 & {$[26]$} & P41 & {$[38]$} \\
\hline P12 & {$[33]$} & P27 & {$[7]$} & P42 & {$[40]$} \\
\hline P13 & {$[11]$} & P28 & {$[37]$} & P43 & {$[42]$} \\
\hline P14 & {$[33]$} & P29 & {$[39]$} & P44 & {$[27]$} \\
\hline P15 & {$[9]$} & P30 & {$[41]$} & P45 & {$[28]$} \\
\hline & & & & P46 & {$[35]$} \\
\hline & & & & & \\
\hline
\end{tabular}

\subsection{Startup and Ecosystem Elemets}

The startup ecosystem was reported to influence each startup cycle [1, 2, 16]. Many suggestions from the author to schedule the development of the ecosystem earlier to satisfy the market demands at the next stage.

\subsection{The Early Stagr of Deeveloping a Startup Business}

Building a startup means seeking new opportunities in the corporate field. There was also realized that many business companies are trying to grow their inventions to keep their businesses alive. When beginning a new company and producing income, startups must have a variety of resources (such as funding [7], skills [24], and innovation [15]. The startup must be prepared with a good entrepreneurship curriculum such that there is a more mature ability to turn inspirational ideas into an actual enterprise.

Selectively, it is crucial to search for partners or promoters willing to entrust their capital to engage in creating a new company. Not only does the new company require the right investors, but investors often want firms that are perceived to benefit from the investment funds offered. Research conducted by [6] suggests realistic options for new 
startup entrepreneurs to use automated processes that offer precise criteria to determine investors' suitability.

The preceding explanation may lead the company to conclude that the design plan will be critical during the early stages of startup development. Before determining which ecosystem elements have the greatest impact on startup business growth, it is critical to consider the role of the startup environment in early startup business growth.

\subsection{The Role of Startup Ecosystem in the Early Stage of Business Startup Development}

\section{Demography}

Building a startup business culture in a new environment started by transferring the small-scale business mindset among local communities to large-scale businesses [10]. [14] Culture's role as one of the factors that affect changes in customer tastes in digital market transition, innovation, and socio-economic conditions. To equip this information, the experience of startups in the past and the present can be excreted. The awareness of the advantages of emerging technology can be directed towards the growth of companies [18]. At last, these resources will bring about creativity for the startup [8].

Growth in stabilization, industrial productivity, and promising startup markets is often influenced by the local circumstances in which the startup was developed [22, 24]. Adequate industry and educational climate can have a positive effect on the market growth for internal startups. So take advantage of the government's innovation and encouragement, then pay attention to the current legislation and policies.

\section{Education}

Business and entrepreneurship disciplines are offered in many universities [15]. The educational institution educates students by recognizing the theory and developing promising young entrepreneur seeds. Most of them also push students to develop new ventures and strengthen their creative abilities in problem-solving around them [26, 29]. This condition shows the university's effectiveness in recognizing the entrepreneurship environment and identifying market strategy [29]. For example, a startup in the field of IoT, their company, is closely connected to researchers in an educational institution [30]. It is necessary to consider our market climate and goals by one of the learning approaches traditionally used to achieve early strategic results [3]. E.g., in the distribution industry, export practices at the beginning are not recommended due to lack of experience and the risk of big failure [5]. Building a startup company can not be isolated from the impact of experts in their field [31].

Based on expertise and experience, creating an effective startup is often decided by who the creator is. In addition to a systematic educational context, the ability to think and act with an entrepreneurial spirit is also extracted from the provision of parental education [15]. Many family-owned entrepreneurs will pursue successors from their own families (children). Moreover, based on family experience, a person can learn to 
succeed in creating a new company without relying on the progress of the family business or the potential prospects for a family business [32].

\section{Entrepreneur}

The history of one's expertise determines how to handle ideas in creating a company [15]. An entrepreneur did not work on his own to create a company. They have team members who are capable and willing to work under the pressure of corporate success, although faced with various challenges in the future. In addition to playing a role in business innovation, an entrepreneur (CEO) is a person who can guide the characteristics of startups that he or she wishes to create (Hanssens, et al., 2016). The changes to CEOs in the next period could impact startups. This situation needs to be considered for the future of startups.

Based on SIA (Social Impact Accelerators) institutions, most entrepreneurs active in the economy are mainly male-led, and many social entrepreneurs are female-led [33]. Startup Managing Directors (MDs) should be selected based on their business expertise and individual mission (emotional and motivational factors), which then played a part in shaping the achievement of the results of the startup [25]. E.g., In the startup software business market, while the founder does not have technical experience, he knows how to discourage incorrect market practices [34].

\section{Finance}

The development concepts of any startup are determined by their stage of development or financial situation [24]. This financial status is also important for startup companies. The position of investors or other supporters of the startup fund has different consequences for the startup sector. Analysis [35] suggests that crowdfunding opportunities financial and non-financial. It can improve credit scores, validate business ideas, and readiness to sell products or services [36]. The growth of the financial technology ecosystem (FinTech) will lead to innovation in the financial system's operational and promote technical innovation in other business processes in the form of internal startup [20].

A sponsor is also an organization that voluntarily offers financial and educational assistance to startup companies [22]. Another category is investors, who typically provide their money to invest in startup businesses. Having investors from an angel group or a venture capital firm may be achieved by entering the acceleration program. They have early access to startup participants [22]. Besides, this acceleration program is also aligned with the government's financial assistance for startups, see study [37]. If it has succeeded in drawing investors, venture capital (VC) investment can begin in the next cycle [7]. From a financial point of view, two types of loans can be considered startups, low-risk loans or higher-risk loans [6].

Investors choose startups as a place to invest not because they pay attention to winning in competition but look at how the business development opportunities they have laid out for the future [35]. The research results conducted by [38] provide information that investors tend to invest in businesses with a similar investment label before. Choosing 
the right target investor through information gathering will be good for a new startup business. Further study of the factors used to properly recommend investors to business beginners in research [38].

\section{Human capital}

The social psychologist's background impacts one's commitment, effectiveness, and entrepreneurial spirit at work [15]. A person's skills play a role in meeting various business needs, such as forming a minimum viable product (MVP), determining business priorities, and handling other technical issues [1]. Startups need availability of qualified human resourceransform business concepts into tangible and profitable forms of business [7] especially when there is influence from third parties at certain events [34, 39] or switch roles to become an agile team at some time [40]. Reacting to these skill needs can be performed by applying the talent's requirements policy when first looking for team members [8]. This personal ability in research [26, 32] significantly influences success in achieving business outcomes.

Building a successful startup must begin with managing the business professionally [16]. A startup must have team members who can handle each business project responsibly and adequately. Especially in this modern era with increasingly rapid technological development, six skills must strengthen to survive in a digital business competition [18, 41]. Information management skills to get more knowledge of technological development and trends in the startup environment. The communication ability can expand the network, both with fellow startup founders, mentors in the accelerator program, especially potential investors. Collaboration skills as teamwork to run a startup business process. Teams with critical thinking will complement each other's thinking patterns when discussing business ideas' maturity. The creativity might help the startup team to manage business ideas using appropriate technology. Then problem-solving skills to solve business problems become opportunities. In addition to managerial skills, technical skills also need to apply business ideas or innovations planned in the early stages of startup development [9].

The government also plays a vital role in managing the skills resources needed in startup businesses [10], such as accelerator programs thastartup founders can followo enhance entrepreneurs' skills and potential [22]. In addition to improving skills, each team member also needs to maintain a stable motivation and strategic action of the business [26] and access resources (partners and experts) that can open excellent business opportunities [28].

\section{Market}

Startups are known as businesses that can damage the traditional market order [31] and penetrate various market sectors. This advantage is due to startup product offerings that always provide innovative solutions for most people [8, 29]. Offering products in the right market is a crucial activity in the early stages of startup development. The first product marketing can sell in a small and appropriate environment by analyzing how similar products survive in a consistent market. Increased knowledge about the target 
market will bring opportunities and changes to the new startup business [8]. This context includes history, current customer demand, and potential forecasting customer needs in the future.

Furthermore, it will lead the future market with maximum results because of the new startup's success in integrating products and target markets [8]. In addition to learning how to build new products for the appropriate target market, choose the right way to deliver the products appropriately to the customers is also needed. In research conducted by [42], innovation can be developed by utilizing social media, such as a community of customers who can provide feedback about product quality [29] or even submit innovation proposals on the products they use. Assistance may also come from sponsors through accelerated new product promotion to the target market [28] and the preparation of mature market access [30].

A variety of methods to expand new startup business marketing can be chosen, one of the most recent social media trends. Social media is defined as a collection of internetbased applications that allow users to create and create content according to their individual needs [42]. These terms are called social marketing activity [31]. This facility will indirectly provide transparency to customers and the broader community to benefit itself in the future. Startup businesses can get much input and voluntary evaluations from product users, learn about customer experience [14], expand knowledge in the context of customer or market needs [42], and improve the quality of smart products [29]. At a software startup, software development at the requirements engineering stage is influenced by market needs and desires, considering the target user's diversity and extent $[29,34]$. However, there issues that need to be addressed in today's digital business, namely the behavior of consumers who are increasingly concerned with privacy and security [43]. Furthermore, the term "fake customer" establishes good business relations but prevents the company from developing a broader target market [44].

\section{Support factors}

The government usually supports several programs to help improve startup businesses' quality and success [22]. In research by [34], having a variety of knowledge needed in startup development can be found in the accelerator program, as in research [22] that utilizes accelerator programs to find an MD correctly. Coaching-session programs can include discussions about business achievements, sharing experiences and knowledge, and recognizing each other like this can foster a startup's confidence for success [4]. Changes in the dynamics of the target market and buyers' interests can be learned from the accelerator participants and mentors assigned to guide. The change in the strategy for managing internal knowledge by following this accelerator program shows that our business's accuracy is called a startup [24]. Participation in kick-off workshops can also increase the positive energy of work and encourage inspiration in the learning environment created by the activity [16]. 
Each program will have different agendas and future design concepts [22], so choosing accelerator programs must followtartup needs [5]. The importance of building enthusiasm and conceptualizing the future design of startup early on is to find the right offer for sales so that startup can provide maximum benefit through the optimum amount of product or service production provided [8]. One of the big goals of accelerators providing learning facilities for startup is facilitating the initial process of attracting investors' attention and interest in the initial startup development [22]. Another advantage for individuals who join is increasing individual learning independence. As for the team, this activity helps hone team skills for success [26].

Start a startup product promotion can utilize social media's several features and functions among the seven blocks described in the study [31]. Begins with introducing the business identity, build relationships with investors or accelerator program owners who can support the development of the new startup, share experiences about startup development, or join the community that will connect to the target customers.

\section{Technology}

Technology can give rise to a variety of innovations [37]. Research [32] show that innovation can present an abundance of new knowledge regardless of its success. Innovations needed by startups in the early stages of development include various aspects, product as the customer solution $[8,20]$ and business processes related to internal-external parties [20] such exploit the market [8]. An example of implementing a business process innovation is adopting a digital business platform to meet the primary business activities attracting consumers' attention, including project advertisements [14]. Earlier business process innovations can affect business value creation [45].

The new lean startup approach is now widely adopted because it influences building innovative business models. The assessment is measured using startup performance during the lean startup approach [46] and compared to its proximity to other relevant strategy tools [27]. In research on lean startup by [46], the process adopted by this approach applies a new feed and iteration to rethink and repair the startup business model. Then involve a variety of related internal and external stakeholders. Test the business processes proposed very carefully and without spending a fortune using the lean startup approach. This test is crucial in building a startup business in the early stages [32, 45], to ensuring that the innovation will be sufficient for business [8]. [14]also believes that new business models can be built based on the conventional technology startup roadmap.

Technology in this section is about innovation, infrastructure, products, and industrial development conditions that must be up-to-date by the business startup [10]. From a consumer perspective, internet technology increases the proportion of startup business values. There is a shift in the value of "trust" into "security services and legitimacy" [43]. The research result [31] showed that three not yet stable business conditions operating in niche markets have attractive user numbers and performance, have unclear 
business models. However, it adopts a business platform because they believe that social networks can support business activities.

Building a startup business does not have to wait for all the resources and ecosystems that are ready and perfect. The learning process to fix deficiencies is still available in several governments and other business partners' programs. At least all of the resources and ecosystems needed to build a new startup have reached the minimum standard to succeed due to various perspectives, especially the distorted development of technology in the business industry [20]. Adopting innovation at the beginning of business development will provide many benefits because the business conditions are not yet rigid [32]. Utilize government cooperation to obtain technological development alliances with minimum risk and potential [37, 47]. Eh new startup requires a collaboration of skills and experience between its founder and team members [34]. In startup development practice, businesses will not only stop examining elements of the ecosystem during the development stage but will continue until the startup can survive in leading its business sector. Entrepreneurs are beginning to explore various industrial sectors to compete with the market-leading startups. This research is still in the process of reviewing several theories and practices on managing ecosystem elements in the early stages of startup development that are influenced by global pandemic conditions that can be found in research journals. As a result, to progress further in the next stages, practitioners will need to conduct additional studies of various research findings and entrepreneurial practices to obtain a comprehensive study of the preparation of startup elements to meet business needs.

References must be sorted according to the display order of citation literature in this paper.

\section{PROMISING TOPICS OF RESEARCH}

After reviewing the research content of the 46 journals analyzed in Figure 4 using the systematic literature method, the researcher discovered that each element of the ecosystem reviewed made three contributions to the business. Those are creating value, suggesting more suitable business alternatives, and improving the performance of the ecosystem elements. Various issues that have led to research on the startup ecosystem's role were brought together to obtain different perspectives on success. The identification results revealed three significant issues underlying this diversity: various business factors, minimum standards for ecosystem elements, and different startup stages as research objects.

The sections below will elaborate on the problems identified to create future research opportunities (illustrated in Figure 5). The conclusion of each category of element contribution results in a statement indicating the need for additional research in startup growth. See Table 4; this journal has not thoroughly addressed the differences in perspectives of researchers presented in reference papers. However, the findings of 
mapping the problems discovered can be used as a reference by other researchers when evaluating the contribution of additional startup components. Some of the roles written startup elements are supposed to provide practitioners with a better understanding of prioritizing startup element management in the early stages of startup growth.

Table 4. Future research mapping

\begin{tabular}{|c|c|c|c|}
\hline $\begin{array}{l}\text { Journal } \\
\text { references }\end{array}$ & $\begin{array}{c}\text { Element } \\
\text { contribution }\end{array}$ & Statement & $\begin{array}{c}\text { Problem } \\
\text { encountered }\end{array}$ \\
\hline 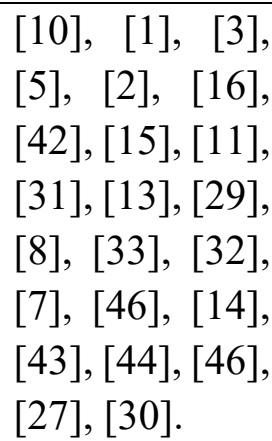 & $\begin{array}{l}\text { Value } \\
\text { creation }\end{array}$ & \multirow{3}{*}{$\begin{array}{l}\text { A variety of business strategies can } \\
\text { be used to create value for each } \\
\text { element of the startup ecosystem. } \\
\text { The difference between each } \\
\text { startup business sector can be seen } \\
\text { in the value expected from each } \\
\text { element. This disparity } \\
\text { demonstrates that the findings of } \\
\text { the study of startup elements' } \\
\text { contributions in the early stages of } \\
\text { startup growth are insufficient to } \\
\text { meet the needs of choosing } \\
\text { strategies for coping with } \\
\text { challenges and improving market } \\
\text { efficiency in the future. According } \\
\text { to startup growth theory, a } \\
\text { company will go through several } \\
\text { phases of development before } \\
\text { becoming a "good and stable" } \\
\text { startup. Future research may look at } \\
\text { the ecosystem requirements that } \\
\text { startups in different industries need } \\
\text { to fulfill and the minimum } \\
\text { preparations required to complete } \\
\text { each startup development process. }\end{array}$} & $\begin{array}{l}\text { Different } \\
\text { business } \\
\text { sector }\end{array}$ \\
\hline $\begin{array}{l}{[34],[29],[12],} \\
{[35],[22],[6],} \\
{[33],[26],[7],} \\
{[40],[14],[37],} \\
{[47],[20],[23],} \\
{[36],[45]}\end{array}$ & $\begin{array}{l}\text { Business } \\
\text { alternative }\end{array}$ & & $\begin{array}{l}\text { Minimum } \\
\text { standard of } \\
\text { ecosystem } \\
\text { element }\end{array}$ \\
\hline $\begin{array}{l}{[4],[3],[18],} \\
{[11],[31],[9],} \\
{[7],[21],[25],} \\
{[38],[36],[28]}\end{array}$ & $\begin{array}{l}\text { Performance } \\
\text { impovement }\end{array}$ & & $\begin{array}{l}\text { Different } \\
\text { stages } \\
\text { startup }\end{array}$ \\
\hline
\end{tabular}

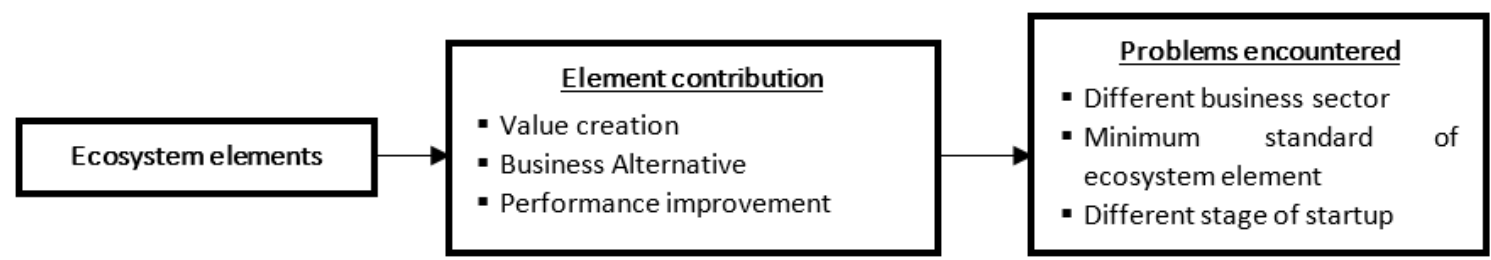

Figure 5. Model research mapping

\section{Topic-1: Minimum standard of ecosystem element to develop a business startup}

Building a startup business must prepare mature resources to not repeat failures like the others, including infrastructure and consideration of applicable state policies. Make 
sure all resources are ready to start a new business. Their respective startup business sectors also measure all ecosystem elements. Perhaps not all ecosystem elements will have a role to play in the early stages of startup business development, either on a pandemic or regularly.

Does it require a certain standard for a business to determine early on the readiness of its resources and the environment, or does it need to wait for investors to obtain funds? Researchers need to look more deeply at this, significantly how most startup s develop well in the early stages of business development and, ideally, how a business develops under a country's auspices.

If the startup meets (ideally) the standard minimum or common version development requirements, it will make it easier for a startup to the next stage of development. To focus on meeting the minimum standard, companies must comply with competitors' conditions and environmental development.

\section{Topic-2: The startup ecosystem needs under the business sector}

Each business sector has its focus, which determines the most critical element in building a startup business. Previous research gaps between theory and practice have found that the contribution of ecosystem elements, in general, is incompatible with their implementation in a particular business sector, which is used as a case study. Every company needs to determine its priority needs precisely to achieve business success. Whether the internal or external ecosystems will influence business success in the early stages of development and continue to be as consistent as before or not.

Particularly in the current pandemic, when most startups try to keep their business as hard as possible. The business sector continues to run as before, not to stop. This condition does not mean that a new business can not be built. Unique needs, new challenges, new business sectors, new opportunities are also emerging as long as we can understand the current problems and solutions. It is the changing needs of these new business people that can be learned to become knowledgeable in the future, such as recognizing different patterns of changes in state policies or even world policies that indirectly impact the business world.

\section{Topic-3: How consistency and change of ecosystem's influence on business}

Today for most countries, the pandemic seems to be the new environment. The countries' development sectors, especially startups, have their respective roles (affected or influenced) when health problems become the main focus. Pandemic conditions become one of those risks not necessarily identified in advance. Adjustment begins with the environment. Although they are used to working under pressure, startups become increasingly depressed, as the pandemic is a global disaster.

The startup environment, which is prepared in advance, must be adjusted suddenly. Maintaining the quality of the startup ecosystem is an important activity that supports business continuity. Each ecosystem element is examined separately in several studies to show its role in developing business innovation. In building a new startup business, 
the ecosystem's development must be considered to contribute appropriately to achieve the business goals and not repeat the startups' failure in the early development stage. Some research predictions in different sectors may use to see and plan for more stable future business development. Generally, the startup business will go through several stages to reach a point of stability. Does the need for each element ecosystem change as the stages through which startups advance. Further research can analyze changes that will make it easier for startups to prepare their ecosystems' stability to meet business needs.

\section{CONCLUSION}

Managing the startup ecosystem needs to maintain business stability and development. Of the eight ecosystem elements translated by [10], [2-6, 18]was revealed one of the main elements that can develop innovation and value in startup products and show ecosystem priorities during the business [1].

Ecosystems in this context [10] are translated as an operating environment and consist of several elements that collaborate [14] and play a role as a learning medium in the startup growth process by optimizing goods on an even larger scale. Ecosystem development influences a new startup development $[3,15]$ because the learning process continues to this day. Startup failures in the first few years in the initial development process due to lack of minimal product value (MPV) still occur $[2,10,16]$. So the literature on understanding ecosystems in early startup development may be needed to achieve appropriate business targets.

Following a deeper understanding and mapping in the early stage of startup development, the research explains various views on the role of ecosystem elements in the development stage. For further research, explore three relevant topics above. Every pioneering startup enterprise can set minimum standards to achieve its closets goals when building the new startup (during the pandemic). Each element of the startup ecosystem needs to be analyzed in greater depth, a change of role can be found, and the needs for the current startup development can be further defined. The difficulties of conquering investors and winning the confidence of customers will require special attention from the founders. It can be even harder to start a startup business during a pandemic. When it could survive in a pandemic, startups still need to prepare strategies to keep their business in a normal (post-pandemic condition) because the influence of startup elements may shift again.

\section{LIMITATION}

The limitations of the analytical aspects of the literature used (2015-2020) have not covered all startup industries that have succeeded or failed to develop. Ecosystem changes in several works of literature also occur under normal conditions. If the results of this study are applied directly, it may not be applicable because now is the initial 
pandemic period. Therefore, we hope that further research can complement the results of this study through the proposed topics that have been offered.

\section{REFERENCES}

[1] N. Tripathi, M. Oivo, K. Liukkunen dan J. Markkula, "Startup ecosystem effect on minimum viable product development in software startups," Information and Software Technology, pp. 77-91, 2019.

[2] P. Dickel, J. Horisch dan T. Ritter, "Networking for the environment: The impact of environmental orientation on start-ups' networking frequency and network size," Journal of Cleaner Production, vol. 179, pp. 308-316, 2018.

[3] F. Fagerholm, A. Hellas, M. Luukkainen, K. Kyllönen dan S. Yaman, “Designing and implementing an environment for software start-up education: Patterns and anti-patterns," The Journal of Systems and Software, vol. 146, pp. 1-13, 2018.

[4] Y. Mansoori, T. Karlsson dan M. Lundqvist, "The influence of the lean startup methodology on entrepreneur-coach relationships in the context of a startup accelerator," Technovation, vol. 84, pp. 37-47, 2019.

[5] N. D. Sarto, D. A. Isabelle dan A. D. Minin, "The role of accelerators in firm survival: An fsQCA analysis of Italian strartups," Technovation, vol. 90, pp. 102$102,2020$.

[6] B. Xu, S. Zhang dan X. Chen, "Uncertainty in financing interest rates for startups," Industrial Marketing Management, vol. 94, pp. 150-158, 2020.

[7] M. Islam, A. Fremeth dan A. Marcus, "Signaling by early stage startups: US government research grants and venture capital funding," Journal of Business Venturing, vol. 33, pp. 35-51, 2018.

[8] N. Feng, C. Fu, F. Wei, Z. Peng dan Q. Zhang, "The key role of dynamic capabilities in the evolutionary process fo a startup to develop into an innovation ecosystem leader: An indepth case study," Journal of Engineering and Technology Management, vol. 54, pp. 81-96, 2019.

[9] H. J. Kim, T. S. Kim dan S. Y. Sohn, "Recommendation of startups as technology cooperation candidates from the perspectives of similarity and potential: A deep learning approach,” Decision Support Systems, vol. 130, pp. 113-229, 2020. 
[10] N. Tripath, P. Seppänen, G. Boominathan, M. Oivo dan K. Liukkunen, "Insights into startup ecosystems through exploration of multi-vocal literature," Information and Software Technology, vol. 105, pp. 56-77, 2019.

[11] T. Kollmann, C. Stöckmann, . T. Niemand dan S. Hensellek, “A configurational approach to entrepreneurial orientation and cooperation explaining product/service innovation in digital vs. non-digital startups," Journal of Business Research, pp. 508-519, 2020.

[12] V. Berg, J. Birkeland, A. Nguyen-Duc, I. O. Pappas dan L. Jaccheri, "Software startup engineering: A systematic mapping study," The Journal of Systems \& Software, vol. 144, pp. 255-274, 2018.

[13] A. Kuckertz, E. S. Berger dan A. Gaudig, "Responding to the greatest challenges? Value creation in ecological startups," Journal of Cleaner Production, vol. 230, pp. 1138-1147, 2019.

[14] G. Guptaa dan I. Bose, "Digital transformation in entrepreneurial firms through information exchange with operating environment," Information \& Management, pp. 103-243, 2020.

[15] R. Badri dan N. Hachicha, "Entrepreneurship education and its impact on students' intention to start up: A sample case study of students from two Tunisian universities," The International Journal of Management Education, vol. 17, pp. 182-190, 2019.

[16] R. Gattringer dan M. Wiener, "Key factors in the start-up phase of collaborative foresight," Technological Forecasting \& Social Change, vol. 153, 2020.

[17] S. J. Makinen dan O. Dedehayir, "Business ecosystem evolution and strategic considerations: A literature review," International ICE Conference on Engineering, Technology and Innovation, pp. 1-10, 2012.

[18] E. V. Laar, A. J. Van Deursen, J. A. Van Dijk dan J. D. Haan, "Measuring the levels of 21 st-century digital skills among professionals working within the creative industries: A performance-based approach," Poetics, vol. 81, pp. 101434, 2020.

[19] H.-F. Hsieh dan S. E. Shannon, "Three approaches too qualitative content analysis," Qual Health Res, vol. 15, pp. 1277-1288, 2005.

[20] M. Palmié, J. Wincent, V. Parida dan U. Caglar, "The evolution of the financial 
technology ecosystem: An introduction and agenda for future research on disruptive innovations in ecosystems," Technological Forecasting \& Social Change, vol. 151, 2020.

[21] F. J. v. Rijnsoeve, "Meeting, mating, and intermediating: How incubators can overcome weak network problems in entrepreneurial ecosystems," Research Policy, vol. 49, 2020.

[22] A. Kuckertz, L. Brandle, A. Gaudig, S. Hinderer, C. A. M. Reyes, A. Prochotta, K. M. Steinbrink dan E. S. Berger, "Startups in times of crisis - A rapid response to the COVID-19 pandemic," Journal of Business Venturing Insights, vol. 13, 2020 .

[23] J. H. Kahle, É. Marcon, A. Ghezzi dan A. G. Frank, "Smart Products value creation in SMEs innovation ecosystems," Technological Forecasting \& Social Change, vol. 156, 2020.

[24] C. Doblinger, K. Surana dan L. D. Anadon, "Governments as partners: The role of alliances in U.S. cleantech startup innovation," Research Policy, vol. 48, pp. 1458-1475, 2019.

[25] T. Meelen, B. Trufer dan T. Schwanen, "Virtual user communities contributing to upscaling innovations in transitions: The case of electric vehicles," Environmental Innovation and Societal Transitions, vol. 31, pp. 96-109, 2019.

[26] L. Cacciolatti, A. Rosli, J. L. Ruiz-Alba dan J. Chang, "Strategic alliances and firm performance in startups with a social mission," Journal of Business Research, vol. 106, pp. 106-117, 2020.

[27] S. Cohen, D. C. Fehder, Y. V. Hochberg dan F. Murray, "The design of startup accelerators," Research Policy, vol. 48, pp. 1781-1797, 2019.

[28] J. Hanssens, M. Deloof dan T. Vanacker, "The evolution of debt policies: New evidence from business startups," Journal of Banking \& Finance, vol. 65, pp. 120-133, 2016.

[29] H. V. Le dan M.-h. Suh, "Changing trends in internet startup value propositions, from the perspective of the customer," Technological Forecasting \& Social Change, vol. 146, pp. 853-864, 2019.

[30] D. Cockayne, "What is a startup firm? A methodological and epistemological investigation into research objects in economic geography," Geoforum, vol. 107, 
pp. 77-87, 2019.

[31] Y. Ekinci, S. Gordon-Wilson dan A. Slade, “An exploration of entrepreneurs' identities and business growth," Business Horizons, vol. 63, pp. 391-401, 2020.

[32] S. Yang, R. Kher dan S. L. Newbert, "What signals matter for social startups? It depends: The influence of gender role congruity on social impact accelerator selection decison," Journal of Business Venturing, vol. 35, 2020.

[33] S. Xu, Q. Zhang, L. Lü dan M. S. Mariani, "Recommending investors for new startups by integrating network diffusion and investors' domain preference," Information Sciences, vol. 515, pp. 103-115, 2020.

[34] C. d. G. Zubielqui dan J. Jones, "How and when social media affects innovation in start-ups. A moderated mediation model," Industrial Marketing Management, vol. 85, pp. 209-220, 2020.

[35] A. Hyytinen, M. Pajarinen dan P. Rouvinen, "Does innovativeness reduce startup survival rates?," Journal of Business Venturing, vol. 30, pp. 546-581, 2015.

[36] J. Paschen, "Choose wisely: Crowdfunding through the stages of the startup life cycle," Business Horizons, vol. 60, pp. 179-188, 2017.

[37] R. Harms, "Self-regulated learning, team learning and project performance in entrepreneurship education: Learning in a lean startup environment," Technological Forecasting \& Social Change, vol. 100, pp. 21-28, 2015.

[38] L. Shi dan A. Miles, "Non-effectual, non-customer effectual, or customereffectual: A conceptual exploration of the applicability of the effectuation logic in startup brand identity construction," Journal of Business Research, vol. 113, pp. 168-179, 2020.

[39] J. Melegati, A. Goldman, F. Kon dan X. Wang, "A model of requirements engineering in software startups," Information and Software Technology, vol. 109, pp. 92-107, 2019.

[40] N. Bocken dan Y. Snihur, "Lean Startup and the business model: Experimenting for novelty and impactLong Range Planning," Long Range Planning, 2020.

[41] J. Pargeter, N. Khreisheh dan D. Stout, "Understanding stone tool-making skill acquisition: Experimental," Journal of Human Evolution, vol. 133, pp. 146-166, 2019. 
[42] A. Ghezzi dan A. Cavallo, "Agile business model innovation in digital entrepreneurship: Lean startup approaches," Journal of Business Research, vol. 110, pp. 519-537, 2020.

[43] A. Ghezzi, L. Gastaldi, E. Lettieri dan A. Martini, "A role for startups in unleasing the distruptive power of social media," International Journal of Information Management, vol. 36, pp. 1152-1159, 2016.

[44] L. Gren, A. Knauss dan C. J. Stettina, "Non-technical individual skills are weakly connected to the maturity of agile practices," Information and Software Technology, vol. 99, pp. 11-20, 2018.

[45] A. Ghezzi, "Digital startups and the adoption and implementation of lean startup approaches: Effectuation, bricolage and opportunity creation in practice," Technological Forecasting \& Social Change, vol. 146, pp. 945-960, 2019.

[46] A. S. Modestino, D. Shoag dan J. Ballance, "Downskilling: changes in employer skill requirements over the business cycle," Labour Economics, vol. 41, pp. 333$347,2016$.

[47] T. Kohler, "Corporate accelerators: Building bridges between corporations and startups," Business Horizons, vol. 59, pp. 347-357, 2016.

[48] T. Oukes, A. v. Raesfeld, A. Groen dan o. b. o. t. P. C. , "Power in a startup's relationships with its established partners: Interactions between structural and behavioral power," Industrial Marketing Management, vol. 80, pp. 68-83, 2019. 
